\title{
Gas Chromatography- Mass Spectrometry Analysis of Phthalide Composition of Celery oil from Apium graveolens L. cultivated in Nigeria.
}

\author{
E. A. Adelakun ${ }^{1} *$, C. Achuenu ${ }^{1,2}$, E. C. Ngurukwem ${ }^{1}$ and D. J. Chuwang ${ }^{1}$. \\ ${ }^{1}$ Department of Chemistry, University of Jos, PMB 2084, Jos, Nigeria. \\ ${ }^{2}$ Department de Chimie Moleculaire (SERCO), Universite Grenoble Alpes. 301 Rue de la Chimie, BP \\ 5338058 Cedex 9, France. \\ *Correspondence email: debola2000@yahoo.com, Tel: +2348037032496 \\ Received 05 February 2021; accepted 28 February 2021, published online 30 March 2021
}

\begin{abstract}
Phthalides are important bioactive constituents of celery plants. The medicinal uses of celery and their characteristic aroma have been linked to the phthalides. In this report, the leaf and stalk oils of celery were extracted either by hydrodistillation or maceration in water and the phthalide constituents of the oils were characterized by gas chromatography-mass spectrometry (GC-MS) analysis. The leaf oil consists mainly of dihydroxyphthalides while the volatile phthalides are the main phthalides in the stalk oil. The phthalide content of the leaf oil and the stalk oil are $39.8 \%$ and $29.95 \%$ respectively. The phthalides identified in the leaf oil are the isomeric compounds of senkyunolide I and senkyunolides ( $\mathrm{J}$ $\& \mathrm{~N}$ ), while the major phthalide constituents of the stalk oil include 3-n- butylphthalide, sedanolide, neocnidilide and sedanenolide/senkyunolide A. The results suggest that the Nigerian celery plant could be considered a good source of phthalides which are known for their nutraceutical properties such as anti-oxidant, antitumor, anti- platelet aggregation, hypotensive, hypoglycemic and hypolipidemic properties. Further phytochemical and pharmacological evaluation of the locally cultivated celery are required in order to exploit the medicinal potentials of the plant for applications in pharmaceutical and cosmetic industries.
\end{abstract}

Keywords- Celery (Apium graveolens L.), Apiaceae, Nigerian Celery plant (Apium graveolens var. dulce), Phthalides, Gas Chromatography- Mass Spectrometry (GC-MS).

\section{Introduction.}

Celery (Apium graveolens L) is a plant that belongs to the Apiaceae family (Umbiliferae). The plants in this family are mostly temperate herbs comprising of about 300 genera and 3000 species. The family has a wide distribution but most of its members are confined to Northern temperate regions and high altitudes in the tropics because they thrive better in the cool weather of temperate regions (1).

The family Apiaceae is one of the many families within the vegetable plants which are rich in phytochemicals such as essential oils, flavonoids, coumarins, polyacetylenes, phthalides and consists of numerous genera of high economic and medicinal value $(2,3)$. Celery is used as a vegetable and spice in soups, salads, and as a garnish in certain dishes. All the plant parts- leaves, stalk, roots and seeds, are useful in various forms. Celery is a biennial plant, it is native to the Mediterranean and North African countries and the genus Apium has about 20 well-known species with several of its varieties found in North America,
Europe, China and North Africa. There are four botanical cultivars of celery plant; namely, Apium graveolens var. rapaceum "celeriac" which is abundantly found in Central Europe, Apium graveolens var. dulce "stalk celery or pascal celery" that is grown in Western Europe and North America, Apium graveolens var. secalinum known as golden or leaf celery and the fourth is Apium smallage $(4,5)$.

A. graveolens has been used for a long time for the treatment of various illnesses because of its therapeutic potentials and it is also used as flavouring agent in several foods owing to the high nutritional value.

The aggregated world production of seed oil of celery was estimated to be 51 tons while only India produces 25 tons among all and the rest of the contribution is made by United Kingdom, Egypt, France, United States of America and China. Different parts of celery contain fatty acids, volatile essential oils, flavonoids, phthalides, vitamins and minerals such as potassium, magnesium and calcium along with $\beta$-carotene, fibers, sodium and folic acid (6). Consequently, different parts of 
the plant are used for preparation of various medicinal formulations in traditional systems of medicines due to their anti-inflammatory, anti-microbial, anti-fungal, anti-bacterial, anti-virus, anti-cancer, anti-spasmodic, gastro-intestinal and anti-oxidant potentials $(7,8)$. Celery is now cultivated globally and it is reported to have wide applications in pharmaceutical, food and cosmetic industries $(1,4,9)$. The economic value of celery plant globally has increased due to its consumption for various medical conditions including the treatment of hypertension and diabetes (10).

In Africa, celery is cultivated in highland regions and for market gardening but more recently also for processing and the food industry. In Nigeria, celery is grown mainly in Jos, Plateau State, where the fresh celery is available in the market (Fig. 1) and many people in Jos metropolis use the celery vegetable mainly for its health benefits. For obvious reasons, the near temperate climate and high altitude of Jos Plateau might be responsible for the favourable climatic

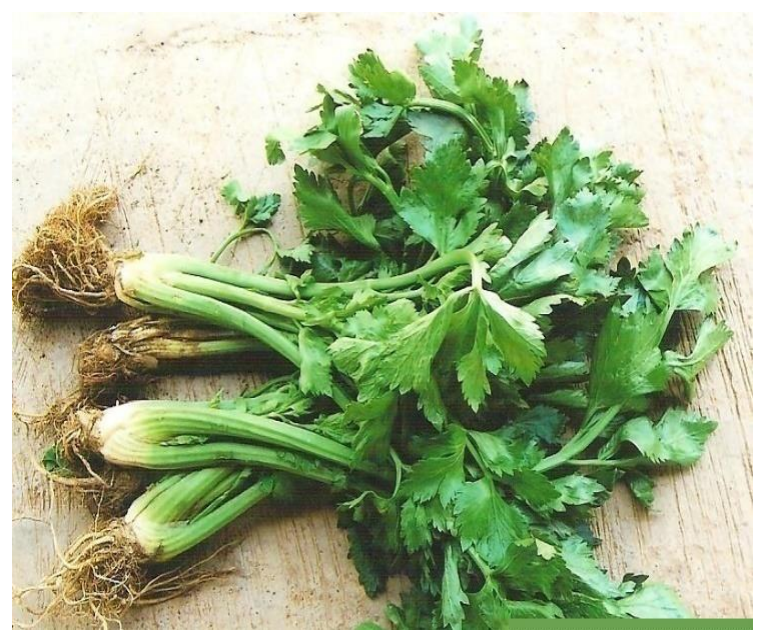

Fig.1 Celery plant purchased from Faringada Market, Jos

The content and constituents of the volatile oils and the identification of characteristic phytochemicals have dominated research on phytochemistry of celery $(6,13)$. However, there has been hitherto no reports on phytochemical profile of celery plant grown in Jos, Plateau State, Nigeria. It is well documented that the phytochemiacls present in medicinal plants are responsible for the therapeutic properties of the plants and that the content of the phytochemicals also vary depending on geographic location, the conditions for the cultivation of celery in Jos. The celery variety that is grown in Jos has been identified as Apium graveolens var. dulce (11). It is noteworthy that many of the other annual/biannual plants and spices of the Apiaceae plants such as carrot, dill, parsley, fennel, coriander and cumin are also cultivated in Jos and they are sold as fresh vegetables or spices in Jos market.

The use of celery as spice and medicine has given an enhanced economic value to the plant and this has also elicited the renewed interest in the scientific studies on the plant. The antioxidant property of celery has been attributed to some of the phytochemicals, namely- flavonoids (apigenin and apiin), essential oil, vitamins A and C present in the plant (12), while the therapeutic effects such as lowering of blood pressure and sedative properties have been associated with the presence of phthalides and the important flavour constituents responsible for the typical aroma of celery are also from the phthalides (Fig. 2).<smiles>CCC/C=C1\OC(=O)C2=C1CC[C@@H](O)[C@H]2O</smiles>

Fig.2. A Phthalide

climatic conditions and the chemotype among others. Consequently, a chemical study is being carried out on celery plant cultivated in Nigeria with a view to identify the phytochemicals present, these chemical information would stimulate further scientific investigations that would provde scientific insight needed to exploit the medicinal potential of the locally produced celery. This work is on the identification of phthalides from the extracts of celery grown in Nigeria. 


\section{Materials and Methods \\ Plant Material}

Celery plant was collected from a farm located at the University of Jos senior staff quarters, Naraguta Campus (permanent site), Jos North Local Government Area of Plateau state , Nigeria in May 2018. The plant material was air dried and the air dried plant material was separated into the plant parts- the leaves and stalk. The different plant parts were crushed separately and used for subsequent to the extractions.

\section{Extraction of Essential Oil}

a) Leaf Material

The crushed leaves $(88 \mathrm{~g})$ of celery were transferred into a $2 \mathrm{~L}$ roundbottom flask and distilled water $(500 \mathrm{ml})$ was added to cover the plant material. Hydrodistillation was then carried out using a Clevenger-type apparatus for three hours. The extracted oil was recovered from the water by extraction with ether $(100 \mathrm{ml}$ $x$ 3times). The ether extract was dried over anhydrous sodium sulphate, filtered and concentrated with a rotary evaporator (at $\left.45^{\circ} \mathrm{C}\right)$, the recovered oil was stored at $4^{\circ} \mathrm{C}$ for the GC-MS analysis. The weight of the oil extracted was $1.5034 \mathrm{~g}(1.7 \%)$.

\section{b) Stalk Material}

The stalk (133.5g) was crushed and extracted by maceration in distilled water $(500 \mathrm{ml})$ for 3 days. The aqueous extract was decanted and filtered over celite using a fritted Buchner funnel. The filtrate was then extracted with ether $(100 \mathrm{ml} \times 3$ times). The ether extract was dried over anhydrous $\mathrm{NaSO}_{4}$, filtered and then concentrated in vacuo using rotary evaporator at $45^{\circ} \mathrm{C}$ and the oil $(0.40 \mathrm{~g})$ was stored at $4^{\circ} \mathrm{C}$ for further analysis. The yield of the stalk oil extracted was $0.3 \%$.

\section{Gas Chromatography - Mass \\ Spectrometry (GC-MS) Analysis of the Essential Oil}

The essential oil extracted from the leaves and the stalk were analysed for their chemical composition using GC/MS AGILENT 7890B, GC System - 5977A, GC Column: HP- 5MS 5\% phenyl methyl silox, 30m $\mathrm{x}$ $250 \mu \mathrm{m} \times 0.25 \mu \mathrm{m}$. The MS Details are as follows: Ionization by electron impact (EI); Analyser is simple Quadripole; Elution condition: Injector temperature: $250^{\circ} \mathrm{C}$, Transferring line temperature- $280^{\circ} \mathrm{C}$; Oven gradient temperature: Initial temperature: $40^{\circ} \mathrm{C}$, maintained $4 \mathrm{~min}$, Gradient: $280^{\circ} \mathrm{C}$ with $20^{\circ} \mathrm{C} / \mathrm{min}$; Final temperature: $280^{\circ} \mathrm{C}$, maintained 4min; Split ratio: 10; Injection volume: $2 \mu 1$. NIST standard reference database was used to assist in the identification of the components.

\section{Results and Discussion}

The GC-MS analysis of the phthalide components of the essential oil of the leaves and stalk of celery grown in Jos revealed the presence of phthalides in both the leaf and stalk oil. The phthalides identified from the leaf and stalk essential oil are shown in Tables 1 and 2 respectively. Figures 3 and 4 show the relative abundance of the essential oil constituents of both the leaf \& stalk, while Fig. 5 shows the MS of 3-nbutylphthalide from the stalk oil. The phthalides presented in this result were not isolated but rather their MS spectra were extracted from the GC/MS spectra of the essential oil of the leaf and stalk of celery respectively. The phthalide content of the leaf oil was calculated from their percentage peak areas and found to be $39.8 \%$ while the phthalide content of the stalk oil was 29.95\%. The results in the Tables indicate that ten phthalides were identified in the leaf oil while eight phthalides were identified in the stalk oil. 


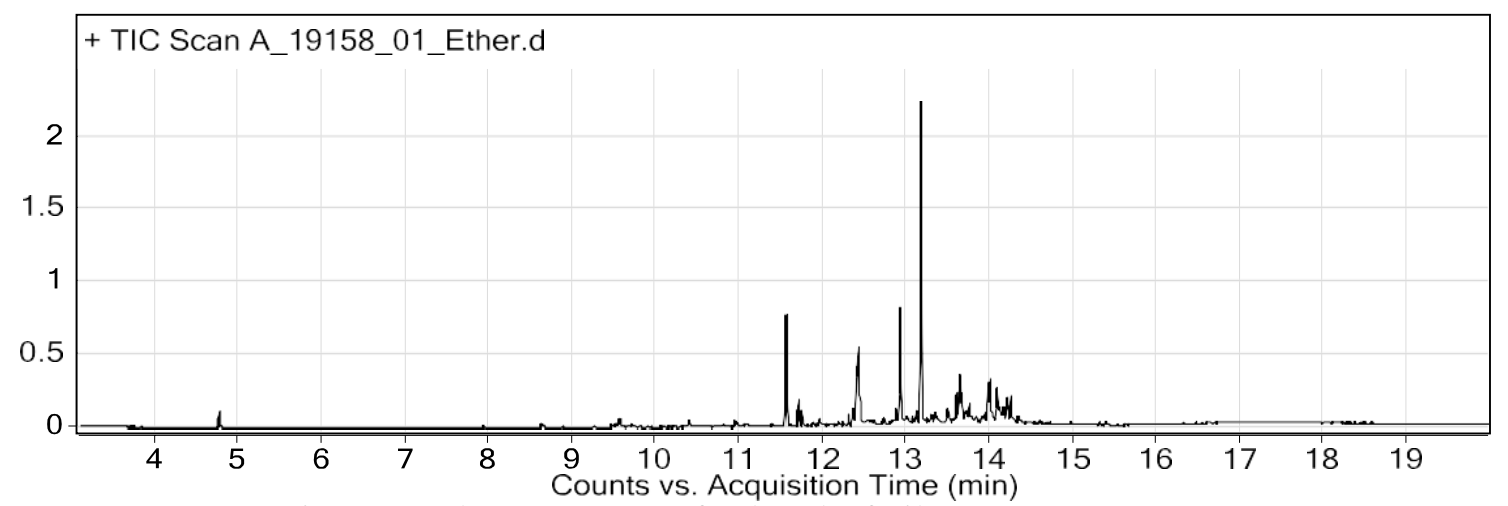

Fig.3. GC chromatogram of celery leaf oil.

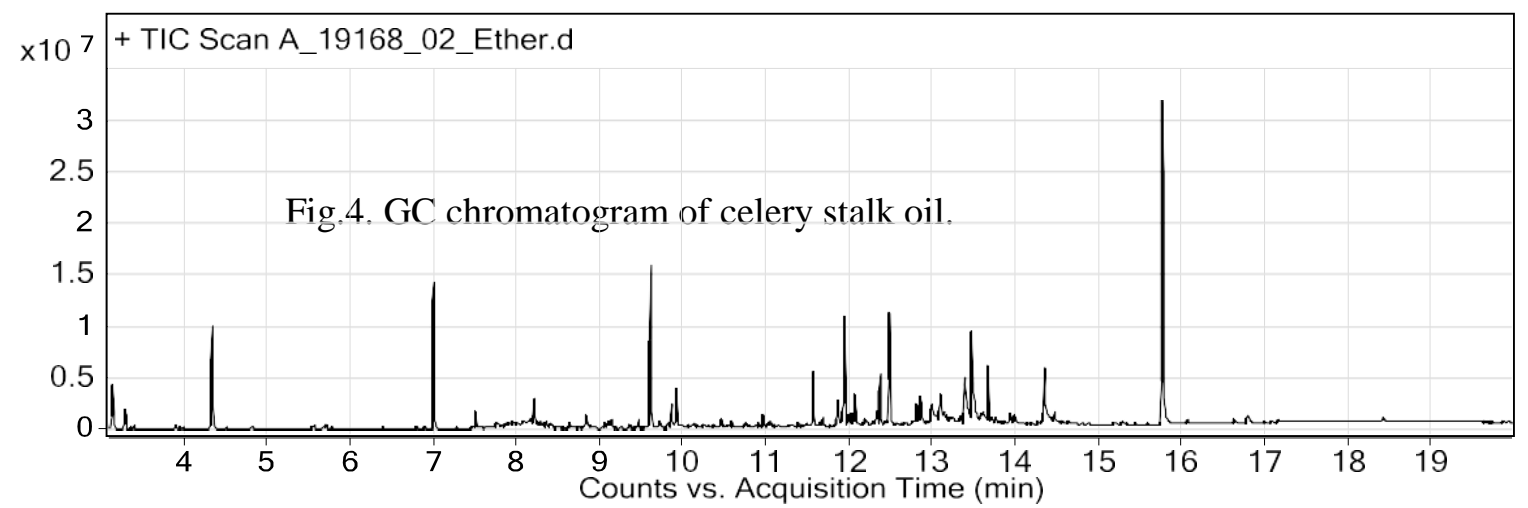

Phthalides from the Leaf Oil.

The phthalides in the leaf oil of celery grown in Jos, have been identified as mixtures of isomeric compounds of Z-6, 7dihydroxyligustilide (Senkyunolide I), E- 6, 7- dihydroxyligustilide and 3- nButyltetrahydro-6,7- Dihydroxyphthalide (Senkyunolides J \& N) (Table 1). The identification of the phthalides was based on the fragmentation patterns observed in their mass spectra as well the structural information obtained from comparison of their mass spectra with the published mass spectral data of the different structural groups of 6, 7-dihydroxyphthalides (14). The diagnostic fragments ions of the dihdroxyphthalides are characteristic of the different structural types and they are useful in structural elucidation of the phthalides.

The mass spectra of the various isomeric dihyroxyphthalides are characterised by successive loss of two molecules of water from their molecular ions but their spectra usually show fragment ions at m/z 209 or 208 or 207 as the first recorded fragment ion suggesting that the molecular ion is very unstable and readily loses water (4). The fragment ions characteristic of the 3- nbutyl-6, 7-dihydroxyphthalides (senkyunolide $\mathrm{J} \& \mathrm{~N}$ isomers) result from the fragment ions$\mathrm{m} / \mathrm{z} 208$ [loss of $\mathrm{H}_{2} \mathrm{O}$ from $\left.\left[\mathrm{M}^{+}\right](-18)\right], 190$ [loss of $\left.2 \mathrm{H}_{2} \mathrm{O}(-36)\right], 162$ [loss of $2 \mathrm{H}_{2} \mathrm{O}+\mathrm{CO}$ (-64)], 152 [loss of $\mathrm{H}_{2} \mathrm{O}+\mathrm{C}_{4} \mathrm{H}_{8}$ (-74)], 144 [loss of $3 \mathrm{H}_{2} \mathrm{O}+\mathrm{CO}(-82)$ and 134 [loss of $\left.2 \mathrm{H}_{2} \mathrm{O}+\mathrm{CO}+\mathrm{C}_{2} \mathrm{H}_{4}(-92)\right]$. The Senkyunolide I isomeric compounds are also characterised by the presence of diagnostic fragment ions- 
$\mathrm{m} / \mathrm{z} 165$ [loss of $\mathrm{H}_{2} \mathrm{O}+\mathrm{C}_{3} \mathrm{H}_{6}(-60)$ ], 161 [loss of $2 \mathrm{H}_{2} \mathrm{O}+\mathrm{CO}(-64)$ ], 147 [loss of $2 \mathrm{H}_{2} \mathrm{O}+$ $\mathrm{C}_{3} \mathrm{H}_{6}(-78)$ and 133 [loss of $2 \mathrm{H}_{2} \mathrm{O}+\mathrm{CO}+$ $\mathrm{C}_{2} \mathrm{H}_{4}$ (-92)] (14). The structures of the 3- nbutyl-6, 7-dihydroxyphthalide isomers and the Z- and E- dihydroxyligustilides (Senkyunolide I stereoisomers) are presented in Fig. 6., however, the stereochemistry of the various isomers would be confirmed after further 2D-NMR studies. The identity of the phthalides from the leaf essential oil reveals the presence of the senkyunolide I-type of dihydroxyphthalides which have not been reported in celery plants $(10,15,17)$.

\section{Phthalides from the Stalk Oil}

The phthalides identified from the stalk oil are mainly the volatile phthalides. There are eight phthalides as shown in Table 2 and six of them are the volatile phthalides. The structure elucidation of these phthalides was based on the comparison of their mass spectra with NIST database and the mass spectral data reported in the literature. The mass spectrum of 3- $\mathrm{n}$ - butylphthalide is characterised by the presence of diagnostic fragment ions at $\mathrm{m} / \mathrm{z} \quad 190\left(\mathrm{M}^{+}\right)$, 133(phthalyl $\left.{ }^{+}\right), \quad 105\left(\mathrm{C}_{6} \mathrm{H}_{5} \mathrm{CO}^{+}\right), \quad 77\left(\mathrm{C}_{6} \mathrm{H}_{5}^{+}\right)$, $51\left(\mathrm{C}_{4} \mathrm{H}_{3}{ }^{+}\right)$as reported by Fazal et al. $(5,17)$. The mass spectrum of the compound at RT $11.91 \mathrm{~min}$, identified as 3-n- butylphthalide [structure 9], shows similar fragment ions (Table 2, Figs.5 \& 7). The identity of the other phthalides were similarly determined based on their fragmentation patterns and in comparison with reported literature data $(5,7,11,17)$. One of the phthalides identified, could be either sedanenolide (structure 10) or senkyunolide A (structure 11) - two isomeric compounds (Fig.7), however, the mass spectral data of the identified phthalide (RT 12.31) agrees with that of senkylunolide $A$ reported by Tang et al. (17). Other volatile phthalides identified were sedanolide (structure 12) and neocnidilide (structure 13), these are also enantiomeric compounds. The two compounds differ in their stereochemistry at C-3a, while the mass spectral data of compound (RT 12.35) matches the mass spectrum of neocnidilide reported by Tang et al., the compound (RT 12.46) with identical mass spectrum was identified using the NIST database as sedanolide. The volatile phthalides identified from the stalk essential oil also include two isomeric compounds of 3- nbutylhexahydrophthalide (structures 14-16), which differ in their stereochemistry either at $\mathrm{C}-3$ or $\mathrm{C}-3 \mathrm{a}$ or $\mathrm{C}-7 \mathrm{a}$ positions. There are eight isomeric compounds of 3- nbutylhexahydrophthalide reported from Apium graveolens and many of them are from Apium graveolens var. rapaceum $(15,18,19)$, the stereochemistry of these isomeric phthalides would be ascertained by 2D- NMR. Two other compounds identified are the dihydroxyphthalides, characterised as 3-n-Butyltetrahydro-6, 7-dihydroxyphthalide and senkyunolide $\mathrm{I}$ on the basis of comparison of their mass spectra with the mass spectral data reported by Zhang et al.(11). The results of the GC- MS analysis show that the major phthalide components of the stalk oil are the 3-n-butylphthalide and sedanolide (GC/MS in Figs.4 \& 5). These volatile phthalides (structures in Fig.7) identified from the stalk oil are phthalides which have been reported to be responsible for the bioactivity of Apium plants $(7,20)$. The phthalide content of both the leaf and stalk oils is low when compared with the percentage composition (74- $76 \%$ in the leaves and $57-74 \%$ in the stalk) reported for Apium graveolens var. Dulce from Tunisia (16).

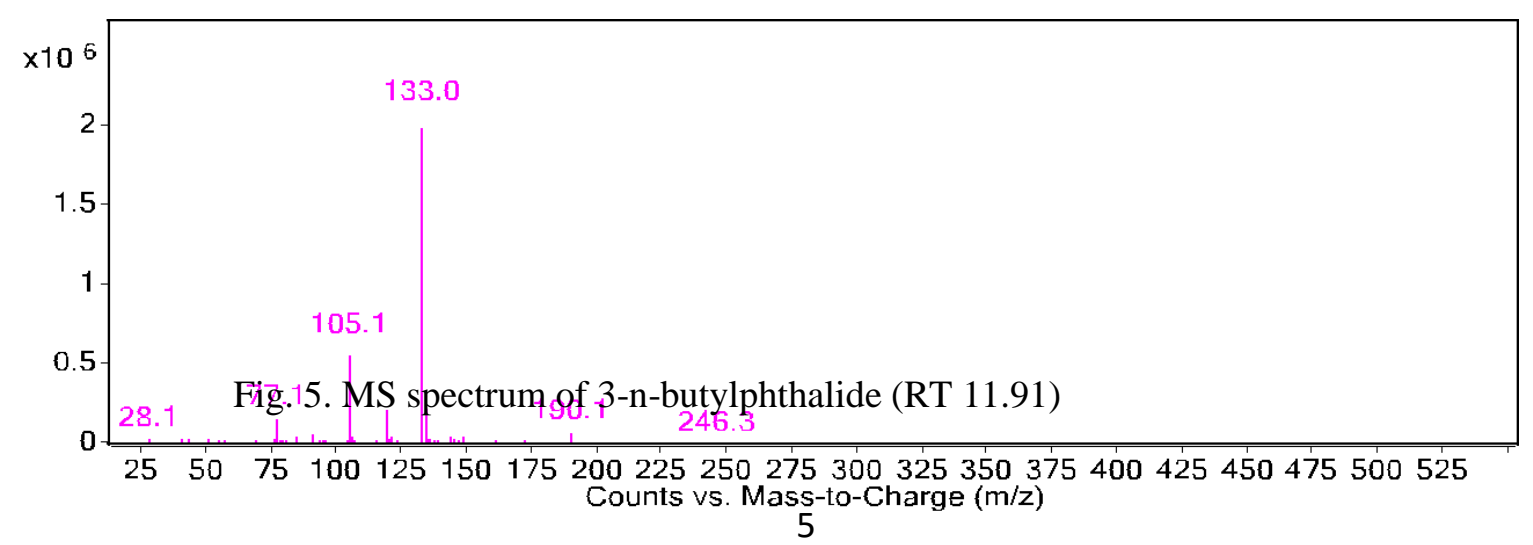


Table 1. MS data of Phthalides identified from Celery Leaf Essential Oil

\begin{tabular}{|c|c|c|c|}
\hline RT & MS data $^{\mathrm{a}}$ & \multicolumn{2}{|l|}{ Phthalide } \\
\hline 12.36 & $\begin{array}{l}207,162,150,147,133,109, \\
108(100), 107,105,91,77, \\
55 .\end{array}$ & \multicolumn{2}{|l|}{ Z- 6,7- dihydroxyligustilide* } \\
\hline 12.39 & $\begin{array}{l}207,191,173,162,150,147, \\
135,121,109,108(100), 107, \\
91,79,77,53 .\end{array}$ & \multicolumn{2}{|l|}{ Z- 6,7-dihydroxyligustilide* } \\
\hline 12.89 & $\begin{array}{l}207,178(100), 163,153,140, \\
135,125,111,109,107,95, \\
81,67,57 .\end{array}$ & $\begin{array}{l}\text { 3-n -Butyltetrahydro-6, } \\
\text { Dihydroxyphthalide** }\end{array}$ & 7- \\
\hline 12.98 & $\begin{array}{l}207,178,163,153,140,135, \\
111(100), 109,108,107,91, \\
79,55 .\end{array}$ & $\begin{array}{l}\text { 3-n- Butyltetrahydro-6, } \\
\text { Dihydroxyphthalide** }\end{array}$ & 7- \\
\hline 13.03 & $\begin{array}{l}207,178,163,153,140,135, \\
111(100), 109,107,95,69, \\
55 .\end{array}$ & $\begin{array}{l}\text { 3-n- Butyltetrahydro-6, } \\
\text { Dihydroxyphthalide** }\end{array}$ & 7- \\
\hline 13.32 & $\begin{array}{l}207,182,163,147,126,123, \\
111,109(100), 95,91,81,79, \\
77,55 .\end{array}$ & Z- 6,7- dihydroxyligustilide* & \\
\hline 13.61 & $\begin{array}{l}194,183,165,150, \quad 137, \\
121,109,93,79(100), 77,55\end{array}$ & E- 6,7-dihydroxyligustilide* & \\
\hline 13.70 & $\begin{array}{l}208,190,182,163,147,137, \\
123,109,107,95,79(100), \\
69,55 .\end{array}$ & E-6,7- dihydroxyligustilide* & \\
\hline 13.94 & $\begin{array}{l}210,192,181,153,135, \\
125(100), 97,79,57 .\end{array}$ & $\begin{array}{l}\text { 3-n -Butyltetrahydro-6, } \\
\text { Dihydroxyphthalide** }\end{array}$ & 7- \\
\hline 13.97 & $\begin{array}{l}210,192,181,153, \quad 135, \\
125(100), 109,79,77,55 .\end{array}$ & $\begin{array}{l}\text { 3-n- Butyltetrahydro-6, } \\
\text { Dihydroxyphthalide** }\end{array}$ & $7-$ \\
\hline
\end{tabular}

$\mathrm{RT}=$ retention time $(\mathrm{min}) ;{ }^{\mathrm{a}} \mathrm{m} / \mathrm{z}$, base peak indicated showing $100 \%$ in parenthesis; *Senkyunolide I stereoisomers; **Senkyunolides J \& N stereoisomers.<smiles>CCC/C=C1\OC(=O)C2=C1CC[C@H](C)[C@H]2C</smiles> 
<smiles>CCC/C=C1/OC(=O)C2=C1CC[C@@H](O)[C@H]2O</smiles>

3<smiles>CCCC[C@H]1OC(=O)C2=C1CC[C@H](O)[C@H]2O</smiles><smiles>CCCC[C@H]1OC(=O)C2=C1CC[C@H](O)[C@H]2O</smiles>

Fig. 6. Isomeric structures of Senkyunolide I (1-4) and Senkyunolides J \& N (5- 8).

Table 2. MS data of Phthalides from the essential Oil of stalk of Celery

\begin{tabular}{|c|c|c|}
\hline RT & MS data $^{\mathrm{a}}$ & Compound \\
\hline 11.84 & $\begin{array}{l}196(\mathrm{M}+), \quad 139(100), \\
111,96,95,82,67,41 .\end{array}$ & 3-n-Butylhexahydrophthalide\# \\
\hline 11.91 & $\begin{array}{l}190(\mathrm{M}+), 148, \quad 133(100), \\
105,77,51 .\end{array}$ & 3-n-Butylphthalide \\
\hline 12.04 & $\begin{array}{l}196(\mathrm{M}+), 149,139(100), \\
111,96,82,67,55\end{array}$ & 3-n-Butylhexahydrophthalide\# \\
\hline 12.31 & $\begin{array}{l}192(\mathrm{M}+), \quad 133, \quad 109, \\
107(100), 105,85,79,77, \\
28 .\end{array}$ & $\begin{array}{l}\text { Senkyunolide } \\
\text { (11)/Sedanenolide* }\end{array}$ \\
\hline 12.35 & $\begin{array}{l}194(\mathrm{M}+), 137,133,109, \\
108(100), 80,79,77,41 .\end{array}$ & Neocnidilide** \\
\hline 12.46 & $\begin{array}{l}194(\mathrm{M}+), \quad 137, \quad 109, \\
108(100), 91,80,79,77, \\
41 .\end{array}$ & Sedanolide** \\
\hline 12.83 & $\begin{array}{l}210, \quad 182, \quad 139, \quad 137, \\
126(100), 125,97,81,79, \\
55 .\end{array}$ & $\begin{array}{l}\text { 3-n-Butyltetrahydro-6,7- } \\
\text { dihydroxyphthalide }\end{array}$ \\
\hline 13.07 & $\begin{array}{l}208,190,165,155,147, \\
133(100), 123,105,95,77, \\
55,28 .\end{array}$ & Senkyunolide I \\
\hline
\end{tabular}

RT, Retention time; ${ }^{a} \mathrm{~m} / \mathrm{z}$, base peak with relative intensity in parenthesis; *stereoisomers; **enantiomers; \# stereoisomers of 3- butylhexahydrophthalide. 
<smiles>CCCCC1OC(=O)c2ccccc21</smiles><smiles>CCCCC1OC(=O)C2=C1CCC=C2</smiles><smiles>CCCC[C@H]1OC(=O)C2=C1CCC=C2</smiles><smiles>CCCC[C@H]1OC(=O)C2=CCCC[C@@H]21</smiles><smiles>CCCC[C@H]1OC(=O)C2=CCCC[C@@H]21</smiles><smiles>[Y4][C@H]1CCCC[C@H]1CCCC</smiles><smiles>CCCC[C@H]1OC(=O)[C@H]2CCCC[C@H]21</smiles><smiles>CCCC[C@H]1OC(=O)[C@H]2CCCC[C@H]21</smiles>

Fig. 7. The volatile Phthalides identified in the stalk essential oil

\section{Conclusion}

The results of this study reveal that the phthalide composition of the leaf and stalk oil of celery grown in Nigeria, show significant difference in their major phthalide constituents and also in comparison with reports on essential oil constituents of celery in other countries $(1,4,13,18,19)$. The leaf phthalides are dominated by the dihydroxyphthalides and none of the volatile phthalides commonly reported in celery essential oil was identified in the leaf oil. However, the stalk oil content differs as it contains mainly the volatile phthalides with the celery aroma compounds, 3- nbutylphthalide and sedanolide, as the major phthalide components. It is a common phenomenon that the phytochemical composition of a plant may vary depending on factors such geographical location, chemotype, or time of harvest among others, and any of these factors may be responsible for the differences observed in the phthalide constituents of the celery plant from Nigeria (20). The findings in this study show that the celery grown in Jos contains phthalides 
which have been reported to be responsible for the bioactivity of celery plants. The presence of these bioactive phthalides in the celery grown in Nigeria suggests that the Nigerian celery could be useful for similar medicinal applications such as anti-oxidant, anti-tumor, anti- platelet aggregation, hypotensive, hypoglycemic and hypolipidemic properties reported for celery plants in other countries (13). Further structural characterization would be carried out to determine absolute stereochemistry of the various stereoisomers as well as pharmacological studies to provide relevant information on the bioactivity potentials of the locally grown celery. This may lead to the domestication of its applications in pharmaceutical and cosmetic industries thereby enhancing the economic fortunes of the farmers and also creating more investment opportunities in the country.

\section{Acknowledgements}

This work was carried out with financial support from Tertiary Education Trust Fund (TETFUND), Nigeria. The authors would like to acknowledge the Office of Research and Development (ORD), University of Jos, Nigeria, for administrative support.

\section{References}

1. M.G. Aćimović.(2017). Nutraceutial potential of Apiaceae. J.-M. Mérillon, K.G. Ramawat (eds.), Bioactive Molecules in Food, Reference Series in Phytochemistry. Springer International Publishers, pp 1-31.

2. N. Margaris, A. Koedam and D. Vokou (1982). Aromatic Plants: Basic and applied aspects. Martinus Nijoff Publishers, pp165- 173.

3. H. B. Sowbhagya (2014). Chemistry, technology and nutraceutical functions of celery (Apium graveolens L.): An overview. Critical Review in Food Science and Nutrition, 54: 389-398.

4. A. Khalil, H. Nawaz, J. B. Ghania, R. Rehman and F. Nadeem (2015). Value added products, chemical constituents and medicinal uses of celery (Apium graveolens L.) - A review. International Journal of Chemical and Biochemical Sciences, 8: 40-48.
5. S. S. Fazal, M. M. Ansari, R. K. Singla and S. Khan (2012). Isolation of 3- n- Butylphthalide an Sedanenolide from Apium graveolens Linn. Indo Global Journal of Pharmaceutical Sciences, 2(3): 258261.

6. A. A. Helay, J. P. Back, E. Mady, M. H. Z. Elderkashy and L. Craker (2015). Phytochemical analysis of some celery accessions. Journal of Medicinally Active Plants, 4(1- 2): 1- 7.

7. D. Liu, C. Xu, L.Zhang, H. Ma, X. Chen, Y. Sui and H. Zhang (2020). Evaluation of bioactive components and antioxidant activity of four celery (Apium graveolens L.) leaves and petioles. International Journal of Food Properties, 23(1):1097- 1109.

8. S. S. Fazal and R. J. Singla (2012). Review on the pharmacognostical and pharmacological characterization of Apim graveolens Linn. Indo Global Journal of Pharmaceutical Sciences, 2(1): 36- 42.

9. W. Kooti, S. Ali- Akbari, M. AsadiSamani, H. Ghadery and D. AshtaryLarky (2014). A review on medicinal plants of Apium graveolens. Advanced Herbal Medicine, 1(1): 4859.

10. B. Salehi, A. Vendihi, C. Frezza and A. Yucetep (2019). Apium plants: Beyond simple foods and phytopharmacological applications. Appl. Sci., 9: 3547- 3586.

11. M. S. Stephen, E. A. Adelakun, J. H. Kanus and M. M. Gideon (2020). Antioxidant activities of extracts from celery leaves (Apium graveolens L.) grown in Jos, Nigeria. International Research Journal of Pure and Applied Chemistry, 21(4): 1- 5.

12. W. Kooti and N. Daraci (2017). A review of the antioxidant activity of celery (Apim graveolens L.). Journal of Evidence Based Complimentary Alternative Medicine, 2:32-40

13. M. Olle and I. Bender (2010). The content of oils of umbelliferous crops and its formation. Agronomy Research, 8(Special issue III): 687696.

14. X. Zhang, H. Xiao, Q. Xu, X. Li, J. Wang and X. Liang (2003). 
Characterization of phthalides in Ligusticum chuanxiong by liquid chromatographic- atmospheric pressure chemical ionization- mass spectrometry. Journal of Chromatographic Science, 41: 428433.

15. G. Lin, S. S. Chan, H. Chung and S. Li (2005). Chemistry and biological activities of naturally occurring phthalides. In studies in Natural Products Chemistry, Atta-ur- Rahman (Ed.)- Elsevier B. V, 32: 611-669.

16. I. H. Sellami, I. Bettaieba, S. Bourgoua, R. Dahmania, F. Limanaa and B. Marzouka (2012). Essential oil and aroma composition of leaves, stalk and roots of celery (apium graveolens var. dulce) from Tunisia. Journal of Essential oil Research, 4(6): 513-521.

17. Y. Tang, M. Zhu, S. Yu, Y. Hua, J. Duan, S. Su, X. Zhang, Y. Lu and A.
Ding (2010). Identification and comparative quantification of bioactive phthalides in essential oils from Si- Wu- Tang, Fo- Shou- San, Radix Angelica and Rhizoma Chuanxiong. Molecules, 15: 341- 351.

18. Z. A. Shojaei, A. Ebrahimi and M. Salimi (2011). Chemical composition of three ecotypes of will celery (Kelussia odoratissima). Journal of Herbs, Spices and Medicinal plants, 17: 62- 68.

19. J. J. Beck and S. Chou (2007). The structural diversity of phthalides from Apiaceae. J. Natural Products, 10(5): 891- 900.

20. O. Choudhary and B. Kaul (1992). Volatile aroma constituents of celery (Apium graveolens L. var. dulce. Indian Perfumer, 36:17. 